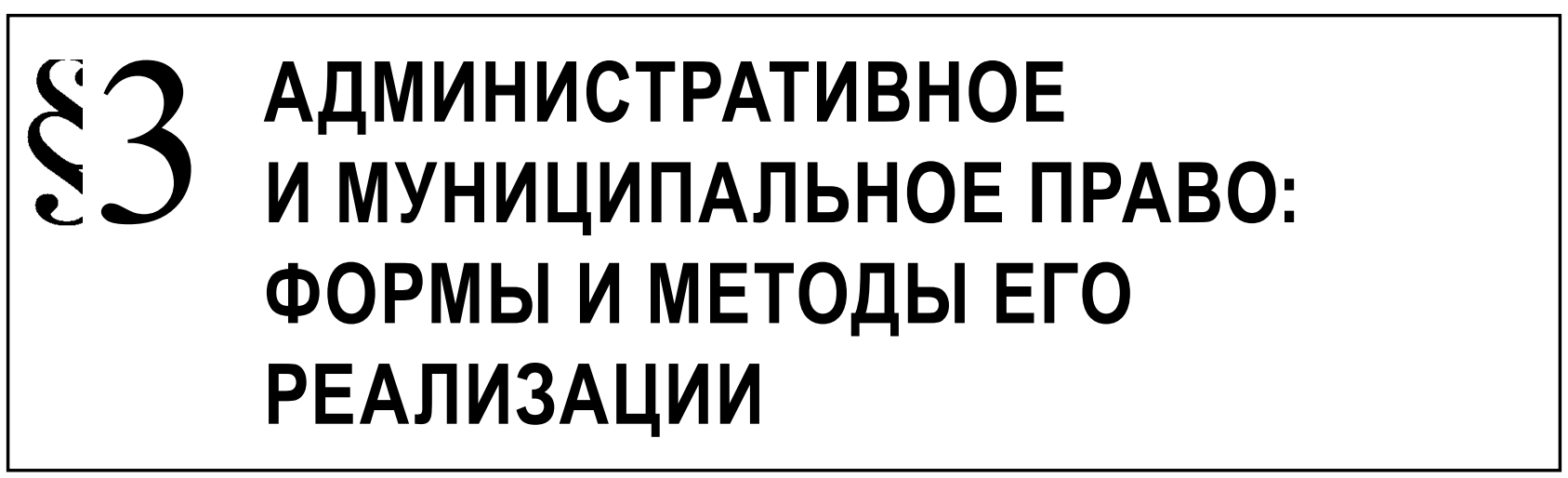

Баранов И.Н.

\title{
МУНИЦИПАЛЬНЫЙ ПРАВОТВОРЧЕСКИЙ ПРОЦЕСС: ПОНЯТИЕ И СТАДИИ
}

Аннотация. Предметом настоящей статьи выступают актуальные проблемы, связанные с реализацией муниципального провотворческого прочесса в условиях российских реалий. В представленной работе анализируется и раскрывается содержание понятий «муниципальное правотворчество» и "муниципальный правотворческий процесс», подвергаются анализу стадии муниципального правотворческого процесса. Констатируется отсутствие единства мнений о содержании муниципального правотворческого прочесса в научной и учебной юридической литературе. На основе изучения позиций профильных исследователей делается вывод о недопустимости смешения ключевых понятий в данной области знаний. Исследуется сущность муниципальных правовых актов, дается их характеристика. При подготовке статьи автором используются такие научные методы познания, как: анализ, синтез, логический и диалектический. Предлагается авторская трактовка понятия "муниципальный правотворческий прочесс», аргументируется необходимость его включения в понятийный аппарат Федерального закона от 6 октября 2003 года №131-Ф3. Обосновывается вывод о том, что контроль исполнения, отмена муниципальных правовых актов или приостановление их действия не могут в полной мере идентифицироваться в качестве стадий муниципального правотворческого прочесса. Предлагаются и аргументируются основные тезисы, ориентированные на совершенствование определения "муниципальный нормативный правовой акт».

Ключевые слова: муниципальное правотворчество, муниципальный правотворческий процесс, муниципальный нормативный процесс, муниципальный правовой акт, органы местного самоуправления, нормотворчество, стадии правотворческого процесса, промульгация, правотворчество, субъекты правотворческого процесса.

Review. The subject of the article is the range of problems of municipal law-making in the Russian reality. The author analyzes and reveals the concepts "municipal law-making" and "municipal law-making process" and the stages of municipal law-making process. The author ascertains the lack of unanimity of views about the content of municipal law-making process in scientific and educational literature on jurisprudence. Having studied the positions of scientists in this sphere, the author comes to the conclusion about impermissibility of merging of key concepts in this sphere of knowledge. The author studies the essence of municipal legal acts and characterizes them. The study is based on the methods of analysis, synthesis, logic and dialectics. The article demonstrates the author's understanding of the concept of "municipal law-making process", argues the necessity of its inclusion in the Federal Law of October 6, 2003 № 131-FZ. The author substantiates the idea that control over implementation, and also abrogation or suspension of municipal legal acts cannot be fully identified as the stages of municipal law-making process. The author offers the ways of improvement of the concept "municipal normative legal act".

Keywords: stages of law-making process, rule-making, local government, municipal legal act, municipal regulatory process, Municipal law-making process, municipal law-making, promulgation, law-making, subjects of law-making process. 
$\Phi$ ункционирование местного самоуправления в современной России показывает, что его неотъемлемым направлением является муниципальный правотворческий процесс, в ходе которого разрабатываются и принимаются муниципальные правовые акты, предназначенные для регулирования деятельности населения муниципальных образований и органов местного самоуправления по решению вопросов местного значения.

Анализ юридической литературы показывает, что в научных трудах, наряду с понятием «муниципальный правотворческий процесс», широко используются как тождественные понятия «муниципальное правотворчество», «муниципальный нормотворческой процесс» и «муниципальное нормотворчество». Такое разнообразие названия важнейшего направления осуществления местного самоуправления представляется некорректным.

Муниципальный правотворческий процесс тесно связан муниципальным правотворчеством. Муниципальное правотворчество можно рассматривать с двух позиций. Во-первых, как интеллектуальный труд людей, независимо от их должностного статуса, оформленный в виде комплекса правил поведения граждан, деятельности органов публичной власти, общественных и производственных объединений, находящихся на территории муниципальных образований. Во-вторых, как целенаправленный профессиональный труд людей, занимающих соответствующие должности в органах публичной власти по выявлению неурегулированных муниципальным правом сфер деятельности органов местного самоуправления, по разработке предложений и идей, предназначенных для включения в нормативные правовые акты, а также по их подготовке.

В связи с этим, на наш взгляд муниципальное правотворчество можно рассматривать как предтечу муниципального правотворческого процесса, которая проявляется в формировании правовых идей и предложений по урегулированию жизнедеятельности местных сообществ, инициирует последующую деятельность по разработке нормативных правовых актов как источников муниципального права.

Говоря о сущности понятия «нормотворчество», то, следует отметить, что эта деятельность представляет собой «придумывание» одной или нескольких правовых норм, не влекущих за собой каких-либо правовых последствий. В процессе осуществления не создаются цельные проекты правовых актов. В связи с этим нормотворчество можно характеризовать как часть более широкого процесса - правотворчества целью которого является разработка правового акта, а не его отдельных норм. Однако многие ученые, как нам представляется, безосновательно используют понятия «нормотворчество» и «правотворчество» как синонимы. Так, например, С.В. Нарутто считает, что муниципальное (местное) нормотворчество - это деятельность по созданию, изменению и дополнению общеобязательных правил поведения по предметам местного значения, осуществляемая в определенном, установленном уставом муниципального образования и иными нормативными актами органов и должностных лиц местного самоуправления в процессуальном порядке [1, c.12]. Вполне определенно по этому вопросу высказался А.В. Юсупов. Он полагает, что нормотворчество на уровне местного самоуправления - это законченный процесс формирования и принятия новых правовых актов в рамках установленных законом процедур [2, с.16] Эти и иные подобные высказывания, на наш взгляд, подтверждают актуальность постановки вопроса о целесообразности единообразного использования соответствующих терминов в научной литературе. Только таким образом может быть достигнута точность понимания конкретных действий и процессов, обусловленных деятельностью по подготовке и принятию правовых актов.

В отношении использования словосочетаний и соответственно понятий «муниципальный правотворческий процесс» и «муниципальный нормотворческий процесс» следует отметить следующее. Ориентируясь на выводы о соотношении понятий «муниципальное правотворчество» и «муниципальное нормотворчество», мы также по указанной причине не ставим знак равенства между понятиями «муниципальный правотворческий процесс» и «муниципальный нормотворческий процесс». Первое понятие значительно шире по своей цели и содержательнее по сравнению со вторым понятием. Именно муниципальный правотворческий процесс является направлением осуществления местного самоуправления. Ведь его результатом является муниципальные нормативных правовые акты, без которых невозможно решать вопросы местного значения.

Предназначение муниципального правотворческого процесса многогранно. Во-первых, данный процесс имеет социальное значение т.е. рассматривается как социальная ценность, определяющая 
уровень правовой культуры субъектов муниципального правотворческого процесса, во-вторых, этот процесс имеет статусное значение, т.е. в результате такой деятельности определяются полномочия субъектов муниципального правотворческого процесса и формы их работы при решении вопросов местного значения, в-третьих, данный процесс способствует вовлечению населения муниципальных образований в разработку нормативных правовых актов. В-четвертых, правотворческий процесс предназначен для расширения системы муниципальных нормативных правовых актов, восполнения правовых пробелов и устранения выявленных коллизий как внутри этой системы, так и по отношению к федеральным и региональным нормативным правовым актам. В-пятых, муниципальный правотворческий процесс предназначен для своевременного реагирования на потребности жителей муниципальных образований, обеспечение соответствия муниципальных правовых актов федеральному законодательству и законом субъектов РФ. В-шестых, этот процесс имеет духовное значение, способствует формированию общественного правосознания, повышению правовой культуры граждан, развитию навыков отражения общественных потребностей в правилах поведения. В-седьмых, этот процесс имеет научное значение, так как каждый принятый нормативный правовой акт обладает определенной новизной и следовательно, дополняет новыми знаниями науку муниципального права.

Представляется, что муниципальный правотворческий процесс имеет и политическую составляющую. Она проявляется в отражении в муниципальных правовых актах властной воли населения муниципальных образований, в контексте с волей всего народа, отражаемой в федеральном законодательстве. Такая взаимосвязь двух уровней выражения коллективной политической воли обусловлена тем, что принимаемые в Российской Федерации законы и иные правовые акты не должны противоречить Конституции РФ (ст.15), принятой 12 декабря 1993 года всенародным голосованием.

Муниципальный правотворческий процесс, равно как и федеральный и региональный правотворческий процесс сориентирован на обеспечение статьи 18 Конституции РФ о том, что права и свободы человека и гражданина определяет смысл, содержание и применение законов, деятельность законодательной и исполнительной власти, а также местного самоуправления. В этом обоснованно видится его итоговая задача и неразрывность с об- щим правотворчеством, сочетаемость его форм и содержания [3, с.212].

В научной и учебной юридической литературе нет единства мнений о содержании муниципального правотворческого процесса. В.И. Фадеев сводил его к подготовке, принятию и вступлению в силу муниципальных правовых актов, что отражает суть статьи 46 Федерального закона от 6 октября 2003 года №131-Ф3 [4, с.385]. Е.С. Шургина характеризует этот процесс более широко. Под таковым она понимает урегулированный нормативными правовыми актами порядок осуществления правотворческой деятельности, включающей внесение в правотворческий орган (внесение на референдум), рассмотрение, принятие, подписание, опубликование и вступление в силу нормативных правовых актов [5, с.69]. Легко заметить, что основное различие приведенных определений муниципального правотворческого процесса сводится к выделению числа действий, необходимых для создания муниципального правового акта. По этому признаку разделяются и многие другие определения муниципального правотворческого процесса.

В то же время, практически все определения муниципального правотворческого процесса объединяет указание на то, что результатом этой общественно полезной деятельности являются муниципальные правовые акты. И действительно, основной целью муниципального правотворческого процесса является принятие муниципальных правовых актов и их обнародование для последующего использования как регуляторов муниципальных правовых отношений.

Понятие «муниципальный правовой акт» раскрывается в статье 2 Федерального закона от 6 октября 2003 года №131-Ф3. Муниципальными правовыми актами считаются решения, принятые населением, органами и должностными лицами местного самоуправления по вопросам местного значения, по вопросам осуществления отдельных государственных полномочий, переданных органам местного самоуправления федеральными законами и законами субъектов РФ, а также по иным вопросам, отнесенным уставом муниципального образования в соответствии с федеральными законами к полномочиям органов местного самоуправления и (или) должностных лиц документально оформленные, обязательные для исполнения на территории муниципального образования, устанавливающие либо изменяющие общеобязательные правила или имеющие индивидуальный характер. Это определение представляется не точ- 
ным, не учитывающим установленные в 2013-2014 годах полномочия субъектов РФ. Однако, оно позволяет сделать вывод о том, что муниципальные правовые акты подразделяются на правовые акты, устанавливающие или изменяющие общеобязательные правила и на правовые акты, имеющие индивидуальный характер. Первая группа муниципальных правовых актов относится к нормативным правовым актам. Именно они представляют особый интерес для исследователей.

По нашему мнению, муниципальный нормативный правовой акт - это структурированная, документально оформленная совокупность общеобязательных правил, принятых населением или компетентным органом местного самоуправления, регулирующих на территории муниципального образования общественные отношения, возникающие при решении вопросов местного значения, при исполнении органами местного самоуправления отдельных государственных полномочий, а также иных полномочий предусмотренной федеральными законами и законами субъектов Российской Федерации и полномочий, не исключенных из их компетенции законами субъектов Российской Федерации.

Как видно из процитированного ранее понятия «муниципальный правовой акт», содержащегося в статье 2 Федерального закона от 6 октября 2003 года №131-Ф3, муниципальные правовые акты могут не только содержать общеобязательные правила, но и иметь индивидуальный характер. Цель нормативного правового акта установить нормы права, т.е. первично урегулировать общественное отношение, определить права и обязанности его участников. Цель ненормативного правового акта обеспечить реализацию предписаний нормативного акта, его применение [6, с.381].

На нормативном уровне нет разъяснения, что понимается под муниципальными правовыми актами индивидуального характера. Однако, на основе анализа статей 43,44,46 Федерального закона от 6 октября 2003 года №131-Ф3, можно предположить, что к таковым относятся ненормативные правовые акты, издаваемые должностными лицами местного самоуправления. При чем, не только по вопросам, касающихся отдельных граждан или юридических лиц, но и более широкому кругу вопросов, в том числе, способствующих решению вопросов местного значения. Этот вывод подтверждается, во-первых, положениями статей $43,46,47,48$ Федерального закона от 6 октября 2003 года №131Ф, в котором называются виды муниципальных правовых актов, в том числе, распоряжения и приказы, традиционно характеризующиеся как акты индивидуального предназначения, во-вторых, достаточно широким кругом лиц, которые вправе вносить проекты любых муниципальных правовых актов в компетентные органы и должностным лицам местного самоуправления, в-третьих, обязательным установлением порядка опубликования (обнародования) всех муниципальных правовых актов, обеспечивающих возможность ознакомления с ними граждан. Эти положения конкретизированы в уставах муниципальных образований, что положительно отражается на муниципальном правотворческом процессе.

В связи с выявлением двух групп муниципальных правовых актов, имеются основания для выделения в рамках муниципального правотворческого процесса двух частей. Одна из них складывается из действий по подготовке муниципальных нормативных правовых актов, вторая - муниципальных правовых актов индивидуального характера.

Сложностью муниципального правотворческого процесса обусловливается объективная потребность в разграничении его на определенные этапы, которые называют стадиями. Можно согласиться с Е.С. Шургиной, которая раскрывает стадии правотворческого процесса органов местного самоуправления и их должностных лиц как ряд последовательных этапов принятия нормативного правового акта местного самоуправления, но каждая из которых решает самостоятельные задачи правотворческой деятельности [5]. Признавая такое определение стадий правотворческого процесса, следует отметить, что субъектом муниципального правотворческого процесса является и население муниципальных образований. При этом, процесс проведения местных референдумов также так же разграничивается на стадии.

Исходя из анализа Федерального закона от 6 октября 2003 года №131-Ф3 можно выделить такие стадии муниципального правотворческого процесса как внесение проекта правового акта в компетентный орган или должностному лицу местного самоуправления, обсуждение проекта, принятие и опубликование (обнародование) муниципального правового акта.

Однако в научной и учебной литературе перечень стадий муниципального правотворческого процесса существенно расширен. Например, М.A. Васильев выделяет девять стадий муниципального правотворческого процесса, в том числе изучение, анализ общественных явлений в муници- 
пальном образовании, выявление потребности их правовой регламентации; определение местных органов-субъектов права, правомочных принять правовое решение, определение вида правового акта; принятие решения о подготовке правового акта; разработка концепции будущего акта; подготовка проекта правового акта; предварительно рассмотрение проекта акта; общественное обсуждение проекта; официальное рассмотрение проекта акта соответствующим органом с соблюдением необходимых, заранее установленных и обнародованных (опубликованных) процедур; принятие правового акта; его окончательное оформление, подписание, опубликование, вступление в законную силу [7, с.28].

Такая поэтапность рассмотрения муниципального правотворческого процесса в целом отражает ход этого процесса. Многие ученые в качестве первых стадий муниципального правотворческого процесса выделяют стадии предшествующие ранее названной официальной стадии внесения проекта муниципального правового акта. Так, например, В.И. Маньковская в качестве таковой видит прогнозирование и планирование муниципального правового акта [8, с.459].

Нам представляется, что выделение такой стадии муниципального правотворческого процесса вполне обоснованно. Ведь перед тем как приступить к разработке муниципального правового акта следует выяснить потребность в регулировании определенных общественных отношений муниципального уровня. Такая деятельность может быть затратна по времени и материальным расходам, так как для этого целесообразно провести социологические исследования, а также провести мониторинг действующих нормативных правовых актов. При этом, такая деятельность должна быть осуществлена людьми, обладающими специальными знаниями и навыками. Ее результаты могут быть основанием для принятия решения о разработке соответствующего нормативного правового акта, учета в нем предложений респондентов, выводов лиц, проводивших мониторинг, что в свою очередь, должно положительно отразиться на качестве проекта и его востребованности практикой.

К стадиям муниципального правотворческого процесса порой относят контроль исполнения и отмену муниципальных правовых актов или приостановление их действия [5, с.459]. По нашему мнению, указанные действия не следует характеризовать как стадию муниципального правотворческого процесса. Как известно, любой вид обще- ственно полезной деятельности ограничивается от другого вида деятельности своей целью. Вполне очевидно, что целью контроля является проверка исполнения конкретных нормативных требований. Поэтому, контроль является самостоятельным видом общественно полезной деятельности, а учет его результатов в правотворческом процессе не меняет его сути. Что касается отмены или приостановки действия правового акта, то такая деятельность не имеет самостоятельного значения, так как она осуществляется путем разработки и принятия соответствующего акта.

Таким образом, представляется возможным рассматривать процесс создания муниципальных нормативных правовых актов в узком и широком смыслах. В узком понимании муниципальный правотворческий процесс закреплен в Федеральном законе от 6 октября 2003 года №131-Ф3 и отражен в уставах муниципальных образований. В этих актах выделены следующие стадии, а именно внесение, обсуждение, принятие и опубликование (обнародование) муниципальных правовых актов.

В доктринальном, широком смысле понятие муниципальный правотворческий процесс включает в себя более широкий перечень действий, а именно, планирование, изучение потребностей целесообразности принятия муниципального правового акта, в том числе проведение мониторинга действующих правовых актов; инициирование принятия муниципального правового акта, в том числе в виде деятельности инициативной группы граждан по организации местного референдума; разработку проекта правового акта, включая его оценку регулятивного воздействия, выявление рисков, которые могут возникнуть после его принятия в виде включения неисполнимых и финансово не обеспеченных статей, статей, противоречащих Конституции РФ и законодательству, отсутствие организационных структур, обеспечивающих исполнение будущего правового акта; официальное внесение проекта правового акта в соответствии с требованиями устава муниципального образования в компетентный орган или должностному лицу; проведение экспертиз, организация общественного обсуждения проекта правового акта и изучение высказанных на публичных слушаниях замечаний и предложений компетентным органом местного самоуправления или уполномоченным должностным лицом; принятие муниципального правового акта путем голосования на местном референдуме или на заседании представительного органа либо его 
подписание главой муниципального образования или другим уполномоченным лицом; промульгация, включающая подписание нормативного правового акта представительного органа главой муниципального образования и его обнародование в официальных СМИ и сети интернет.

Представляется, что наличие доктринального широкого понимания муниципального правотворческого процесса позволяет разработчикам муниципальных правовых актов учесть весь целесообразный набор действий, обеспечивающих принятие муниципальных нормативных правовых актов.

Мы считаем, что муниципальный правотворческий процесс - это осуществляемая на основе комплексных планов целенаправленная цикличная деятельность населения и органов местного самоуправления по выявлению потребностей в правовом регулировании решения вопросов местного значения и других вопросов, а также разработка, обсуждение, оценка и принятие муниципальных нормативных и иных правовых актов, их промульгация в нормативно установленном порядке.

Это определение предлагается включить в понятийный аппарат Федерального закона от 6 октября 2003 года №131-Ф3, содержащийся в его второй статье. Таким образом, во-первых, будет отмечена вовлеченность населения в правотворческий процесс, что соответствует концепции местного самоуправления и положениям статьи 3 и 130 Конституции РФ, соответствующим нормам названного Федерального закона и уставов муниципальных образований, подтверждено право населения решать вопросы местного значения на местных референдумах и сходах, а право граждан участвовать в публичных слушаниях и собраниях, во-вторых, расширит и узаконить перечень стадий муниципального правотворческого процесса путем включения в него таких стадий как планирование, выявление потребностей правового регулирования общественных отношений на муниципальном уровне, оценка и экспертиза проектов правовых актов и их промульгация. В конечном счете будет определен весь объем муниципального правотворческого процесса, что положительно отразится на его результатах.

Формирование местного самоуправления в Российской Федерации приходится на начало 90-х годов XX столетия. Это был период постепенного ослабления власти, завершившийся прекращением деятельности Верховного Совета России (октябрь 1993 года) и последующим упразднением в течение двух следующих лет местных Советов народных депутатов. В процессе реализации принятых в этот период указов Президента РФ [9-12] эти органы сменили органы местного самоуправления. Они стали укрепляться после принятия всенародным голосованием 12 декабря 1993 года Конституции РФ. С одной стороны конституционные нормы обеспечивали самостоятельное развитие местного самоуправления, а с другой - гарантировали его неразрывную связь с государственной властью. Неразрывная связь с государством обусловлена признанием местного самоуправления как одной из конституционных основ, наличием общих правовых регуляторов, близкой по содержанию организационной основой и, что особо важно, единым источником публичной власти. Согласно части 2 статьи 3 Конституции РФ, народ осуществляет свою власть непосредственно, а также через органы государственной власти и органы местного самоуправления. Такое соотношение государственной и муниципальной власти дает основание для вывода о том, что муниципальный правотворческий процесс является своеобразным продолжением и завершением федерального и регионального правотворческого процессов. Такое единение проявляется в том, что наиболее важные нормативные правовые акты-законы, уставы муниципальных образований принимают представительные органы, а также в разграничении правотворческого процесса на определенной стадии. При этом в основе всех видов правотворческой деятельности находится Конституция РФ, а в правотворческом процессе используется единая методология.

В то же время имеются и различия в осуществлении федерального, регионального и муниципального правотворческого процессов. Эти отличия проявляются в разных целях и разном содержании соответствующих процессов. Результатом федерального и регионального правотворческого процессов являются нормативные правовые акты, обладающие большей юридической силой по сравнению с муниципальными правовыми актами. Для муниципального правотворческого процесса характерна ограниченность действия муниципальных правовых актов территорией муниципального образования, более активное участие населения в правотворческой деятельности, сокращенные временные сроки разработки и принятия муниципальных правовых актов, а также более высокая конкретизация их предмета. Но эти особенности муниципального правотворческого процесса не отражаются на его характеристике как составной 
части общего правотворческого процесса в Российской Федерации, т.е. деятельности публичных органов по созданию законов и других нормативных правовых актов. Эта особенность муниципального правотворческого процесса позволяет учитывать при разработке и принятии правовых актов муниципального уровня, лучший опыт разработки и принятия федеральных и региональных законов и таким образом повышать их качество и регулятивное предназначение.

\section{Библиография:}

1. Нарутто С.В. Основные правила юридической техники разработки концепции муниципальных нормативных правовых актов по самоорганизации населения.// С.В. Нарутто,А.С. Пигалкин, Л.А. Плотникова, Хабаровск, 2003. $486 \mathrm{c.}$

2. Юсупов А.В. Нормотворчество на уровне местного самоуправления. Волгоград, 2004. 170с.

3. Калинин А.Ю. Местное самоуправление в современной России : вопросы теории, истории, практик / Под ред. С.А. Комарова. СПб, 2012.348c.

4. Кутафин О.Е., Фадеев В.И. Муниципальное право Российской Федерации. Уч.-3-е изд.-М.:Проспект,2010. 672с.

5. Шургина Е.С. Муниципальное право Российской Федерации : учеб. - 2-е изд., перераб. и доп. - М.: ТК Велби, Издво Проспект, 2007. - 672 с.

6. Авакьян С.А., Тимофеев Н.С., Пешин Н.Л., Сивицкий В.А., Лютцер В.Л. Муниципальное право России: Учебник. М.: Проспект, 2010.544c.

7. Васильев М.А. Нормотворческий процесс в муниципальных образованиях: организация и технология. Обнинск.2002. 88с.

8. Маньковская В.И, Порядок разработки и принятия локальных нормативных актов // Нормография // под ред. Г.А. Арзамасова. М.,2007. 591с.

9. Указ Президента РФ №1617 от 9 октября 1993 года «0 реформе представительных органов власти и органов местного самоуправления в Российской Федерации».

10. Указ Президента Рф №1760 от 26 октября 1993 года «0 реформе местного самоуправления в Российской Федерации».

11. Указ Президента РФ №2265 от 22 декабря 1993 года «О гарантиях местного самоуправления в РФ».

12. Указ Президента РФ №557 от 21 марта 1994 года «0 мерах по обеспечению реформы местного самоуправления».

13. Алешкова Н.П. Муниципальное правотворчество: понятие и сущность // Юридические исследования. - 2013. 7. - C. 67 - 87. DOI: 10.7256/2409-7136.2013.7.8776. URL: http://www.e-notabene.ru/lr/article_8776.html

\section{References (transliterated):}

1. Narutto S.V. Osnovnye pravila yuridicheskoi tekhniki razrabotki kontseptsii munitsipal'nykh normativnykh pravovykh aktov po samoorganizatsii naseleniya.// S.V. Narutto,A.S. Pigalkin, L.A. Plotnikova, Khabarovsk, 2003. 486s.

2. Yusupov A.V. Normotvorchestvo na urovne mestnogo samoupravleniya. Volgograd, 2004. 170s.

3. Kalinin A.Yu. Mestnoe samoupravlenie v sovremennoi Rossii : voprosy teorii, istorii, praktik / Pod red. S.A. Komarova. $\mathrm{SPb}, 2012.348 \mathrm{~s}$.

4. $\quad$ Kutafin O.E., Fadeev V.I. Munitsipal'noe pravo Rossiiskoi Federatsii. Uch.-3-e izd.-M.:Prospekt,2010. 672s.

5. Shurgina E.S. Munitsipal'noe pravo Rossiiskoi Federatsii : ucheb. - 2-e izd., pererab. i dop. - M.: TK Velbi, Izd-vo Prospekt, 2007. $-672 \mathrm{~s}$.

6. Avak'yan S.A., Timofeev N.S., Peshin N.L., Sivitskii V.A., Lyuttser V.L. Munitsipal'noe pravo Rossii: Uchebnik. M.: Prospekt, 2010.544s.

7. Vasil'ev M.A. Normotvorcheskii protsess $\mathrm{v}$ munitsipal'nykh obrazovaniyakh: organizatsiya i tekhnologiya. Obninsk. 2002. 88s.

8. Man'kovskaya V.I, Poryadok razrabotki i prinyatiya lokal'nykh normativnykh aktov // Normografiya // pod red. G.A. Arzamasova. M.,2007.591s.

9. Ukaz Prezidenta RF №1617 ot 9 oktyabrya 1993 goda «0 reforme predstavitel'nykh organov vlasti i organov mestnogo samoupravleniya v Rossiiskoi Federatsii».

10. Ukaz Prezidenta Rf №1760 ot 26 oktyabrya 1993 goda «0 reforme mestnogo samoupravleniya v Rossiiskoi Federatsii».

11. Ukaz Prezidenta RF №2265 ot 22 dekabrya 1993 goda «0 garantiyakh mestnogo samoupravleniya v RF».

12. Ukaz Prezidenta RF №557 ot 21 marta 1994 goda «0 merakh po obespecheniyu reformy mestnogo samoupravleniya».

13. Aleshkova N.P. Munitsipal'noe pravotvorchestvo: ponyatie i sushchnost' // Yuridicheskie issledovaniya. - 2013. - 7. C. 67 - 87. DOI: 10.7256/2409-7136.2013.7.8776. URL: http://www.e-notabene.ru/lr/article_8776.html 